\title{
Estrutura genética e sistema de acasalamento de Piper hispidinervum
}

\author{
Lúcia Helena de Oliveira Wadt ${ }^{(1)}$ Paulo Yoshio Kageyama(2) \\ (1)Embrapa Acre, Caixa Postal 321, CEP 69908-970 Rio Branco, AC. E-mail: lucia@cpafac.embrapa.br (2)Escola Superior de Agricultura Luiz \\ de Queiroz, Dep. de Ciências Florestais, Av. Pádua Dias, 11, CEP 13418-970 Piracicaba, SP. E-mail: kageyama@esalq.usp.br
}

\begin{abstract}
Resumo - A pimenta-longa (Piper hispidinervum C. DC.) arbusto encontrado em áreas antropizadas no Estado do Acre, possui expressiva importância econômica decorrente da presença de safrol em seu óleo essencial. O objetivo deste trabalho foi avaliar a estrutura genética e o sistema de acasalamento dessa espécie, utilizando marcadores RAPD (polimorfismo de DNA amplificado ao acaso). A diversidade genética entre e dentro de populações naturais foi avaliada em 13 populações do Vale do Rio Acre, distribuídas nas Regiões do Baixo e Alto Acre. A taxa preferencial de cruzamento foi estimada em 25 famílias de polinização livre de uma população do Município de Assis Brasil, Acre. A espécie apresentou diversidade genética estruturada no espaço segundo um padrão de isolamento por distância. A maior parte da variabilidade genética foi encontrada dentro das populações, porém a diferenciação entre populações, como um todo, foi alta $\left(\theta_{P}=0,28\right)$. O agrupamento das populações, pela distância genética $\left(\phi_{\mathrm{ST}}\right)$ entre elas, mostrou dois grupos distintos, os quais representam as regiões do Alto Acre e Baixo Acre. A AMOVA mostrou que 20,61\% da variabilidade total está entre essas duas regiões. A taxa de cruzamento multilocos foi estimada em 1,033, evidenciando que a espécie é alógama. A estimativa do coeficiente de endogamia F não diferiu de zero e os cruzamentos ocorreram preferencialmente entre indivíduos não-aparentados.
\end{abstract}

Termos para indexação: pimenta, RAPD, variação genética, cruzamento.

\section{Genetic structure and mating system of Piper hispidinervum}

\begin{abstract}
Long pepper (Piper hispidinervum C. DC.) is a small tree with high commercial value found in areas under anthropic influence in the State of Acre, Brazil. The genetic structure and mating system of $P$. hispidinervum were evaluated using RAPD markers. The genetic diversity within and between natural populations were evaluated in 13 populations in the Basin Acre River - Western Brazilian Amazon. Twenty five open-pollinating families in a population located in Assis Brasil were evaluated to estimate the preferential crossing rate. Genetic diversity was observed, revealing that this species is spatially structured according to a pattern of isolation by distance. Most of the genetic variability was found within populations, and the variation between populations was also high $\left(\theta_{\mathrm{P}}=0.28\right)$. Two distinct groups were formed, based on genetic distances $\left(\phi_{\mathrm{ST}}\right)$, representing the Upper Acre and Lower Acre watersheds. By AMOVA, 20.61\% of the total variability occurs between those two watershed regions. The multilocus crossing rate was estimated at 1.033, the estimate of the inbreeding coefficient $(\mathrm{F}) \mathrm{did}$ not vary from zero, and the crosses preferentially occurred between unrelated individuals.
\end{abstract}

Index terms: pepper, RAPD, genetic variation, crossbreeding.

\section{Introdução}

O processo de sucessão corresponde à recuperação de clareiras abertas ou áreas desmatadas, decorrentes de diversos tipos de perturbação. A área desmatada afeta o microclima local que, por sua vez, determina o estabelecimento de diferentes espécies em função do grupo ecológico a que pertencem (Kageyama et al., 1992).

Resultados obtidos em laboratório indicam que P. hispidinervum é uma espécie típica de ambientes abertos, apresentando sementes com baixa longevidade em condições naturais. Em áreas de pastagem, apresenta banco de sementes restrito, com dispersão durante o ano todo, sendo considerada uma espécie pioneira antrópica, por colonizar áreas perturbadas (Almeida, 1999).

As populações naturais de $P$. hispidinervum são densas, com domínio dessa espécie sobre as demais. Estudos sobre a produção e dispersão de sementes de P. hispidinervum revelaram uma baixa produção em 
indivíduos isolados ou espiguetas ensacadas, sugerindo a existência de certo grau de auto-incompatibilidade (Silva \& Oliveira, 2000). Também foi evidenciado que quanto maior a distância da planta-mãe, maior o número de sementes dispersas, confirmando a hipótese de dispersão por aves ou morcegos, sugerida por Almeida (1999).

Em populações naturais, a distribuição da variabilidade genética é influenciada pelo modo de reprodução, sistema de acasalamento, tamanho da população, distribuição geográfica e fluxo gênico da espécie (Hamrick, 1983).

A maneira mais usual de se conhecer o sistema de acasalamento de uma espécie é pela estimativa da taxa de cruzamento (t). Marcadores RAPD (polimorfismo de DNA amplificado ao acaso), embora de caráter dominante, têm sido utilizados para estimar parâmetros genéticos que definem a estrutura de populações (Ayres \& Ryan, 1999; Keller, 2000) e a taxa de cruzamento (Gjuric \& Smith Junior, 1996; Gaiotto et al., 1997). No entanto, Bekessy et al. (2003) alertam para o uso desse tipo de marcador quando o objetivo é obter informações sobre o potencial adaptativo das populações, pois verificaram que marcadores neutros não são apropriados para tal finalidade.

O balanço entre o sistema de acasalamento de uma espécie e a deriva genética é um fator muito importante a ser considerado na conservação ou manejo de recursos genéticos, pois em espécies alógamas, populações pequenas podem favorecer a depressão por endogamia (Barrett \& Kohn, 1991). Assim, o conhecimento da estrutura genética e a determinação da forma preferencial de acasalamento de uma espécie são fundamentais para definir o manejo adequado ou a sua domesticação.

O objetivo deste trabalho foi avaliar a estrutura genética e o sistema de acasalamento em populações naturais de $P$. hispidinervum, usando marcadores RAPD.

\section{Material e Métodos}

Treze populações naturais de $P$. hispidinervum, distribuídas em oito municípios do Vale do Rio Acre, foram avaliadas para estimativa da sua estrutura genética (Tabela 1). De cada população, foram amostrados, aleatoriamente, 23 indivíduos, coletando-se de cada um quatro folhas jovens e expandidas, as quais foram secadas em sílica gel. O protocolo de extração e amplificação utilizado foi segundo Ferreira \& Grattapaglia (1996). Foram utilizados oito primers da Operon
Technologies (OP-A12, OP-B08, OP-B11, OP-C06, OP-D02, OP-D11, OP-D12 e OP-D20).

Os locos RAPD foram avaliados pela presença (1) e ausência (0) de bandas, obtendo-se uma matriz de fenótipos moleculares. Foram calculados os porcentuais de polimorfismo total e de cada população; as distâncias genéticas entre os pares de populações; e a distribuição da variabilidade genética entre e dentro de populações e regiões geográficas. As estimativas das distâncias genéticas e da variabilidade genética entre populações foram calculadas usando o software AMOVA (Análise da Variância Molecular) e o agrupamento das populações foi feito pelo método UPGMA (Método da Média Aritmética não Ponderada)) (NTSYS-pc versão 1.70), sendo construído um dendrograma para a visualização dos grupos.

Os mesmos dados foram analisados simulando-se equilíbrio de Hardy-Weimberg em todas as populações. Foram feitas estimativas das frequiências alélicas de cada população; da porcentagem de locos polimórficos em cada população; e das estimativas de teta $(\theta)$, pelo método de Weir \& Cockerham (1984), usando-se o software TFPGA (Ferramentas para Análise de Genética de População). As estimativas de $\theta$ correspondem à estatística-F $\mathrm{F}_{\mathrm{ST}}$ de Wright, onde $\theta_{\mathrm{P}}$ refere-se à diferenciação genética entre grupos e $\theta_{S}$ à diferenciação entre populações. A fim de se diminuir o viés nas estimativas das frequiências alélicas, estas foram estimadas segundo o método descrito por Lynch \& Milligan (1994), baseado na Expansão de Taylor.

Para o cálculo da taxa de cruzamento, foram avaliadas 25 famílias amostradas na população de Assis Brasil, AC. De cada planta-mãe foram coletadas sementes

Tabela 1. Identificação e localização de treze populações naturais de Piper hispidinervum amostradas no Vale do Rio Acre, AC.

\begin{tabular}{|c|c|c|c|c|c|}
\hline Pop. & Região & Código & Município & \multicolumn{2}{|c|}{ Localização (UTM) } \\
\hline 1 & Baixo Acre & Acrel & Acrelândia & 19L 711287 & 8884113 \\
\hline 2 & Alto Acre & Assis & Assis Brasil & $19 \mathrm{~L} \quad 442555$ & 8794784 \\
\hline 3 & Alto Acre & Bra 13 & Brasiléia & $19 \mathrm{~L} \quad 520858$ & 8802965 \\
\hline 4 & Alto Acre & Bra 17 & Brasiléia & $19 \mathrm{~L} \quad 510416$ & 8786819 \\
\hline 5 & Alto Acre & Bra 54 & Brasiléia & $19 \mathrm{~L} \quad 497193$ & 8805734 \\
\hline 6 & Alto Acre & Bra 78 & Brasiléia & $19 \mathrm{~L} \quad 465092$ & 8805241 \\
\hline 7 & Baixo Acre & Bujari & Bujari & $19 \mathrm{~L} \quad 607513$ & 8908317 \\
\hline 8 & Baixo Acre & Capalc & Capixaba & $19 \mathrm{~L} \quad 639885$ & 8847396 \\
\hline 9 & Baixo Acre & Capbol & Capixaba & $19 \mathrm{~L} \quad 644340$ & 8825577 \\
\hline 10 & Baixo Acre & Plac & Plácido de Castro & $19 \mathrm{~L} \quad 690596$ & 8859420 \\
\hline 11 & Baixo Acre & Seng & Sen. Guiomard & $19 \mathrm{~L} \quad 648111$ & 8875996 \\
\hline 12 & Alto Acre & Xapar & Xapuri & $19 \mathrm{~L} \quad 610795$ & 8829813 \\
\hline 13 & Alto Acre & Xapmar & Xapuri & $19 \mathrm{~L} \quad 560785$ & 8813626 \\
\hline
\end{tabular}


para produção de mudas e constituição das progênies. Após três meses do plantio no campo experimental, foram coletadas folhas de 15 indivíduos de cada família para análise de marcadores RAPD. Folhas das plantasmãe também foram coletadas para análise.

Foram utilizados nove primers da Operon Technologies (OP-B11, OP-D02, OP-D11, OP-D12, OP-AA11, OP-AA19, OP-AB01, OP-AB05 e OP-AB18). Os fenótipos moleculares das progênies e os genótipos maternos, estimados com base na progênie, foram analisados pelo programa MLDT (Estimativa de Cruzamento Multilocus com Marcadores Dominantes), desenvolvido por Ritland (1990), o qual estima a taxa de fecundação cruzada multilocus da população (tm), a taxa de fecundação cruzada "singlelocus" (ts), as frequiências alélicas da população (pi), o coeficiente de endogamia da geração dos genitores $(\mathrm{F})$, a taxa de cruzamento preferencial entre indivíduos aparentados ( $\mathrm{tm}$ - ts), e a taxa de cruzamento para cada família.

Cada loco RAPD foi avaliado pelo teste qui-quadrado, quanto à aderência ao modelo misto de reprodução. A variância dos parâmetros avaliados foi estimada por 1.000 reamostragens (bootstraps) feitas dentro de famílias.

O coeficiente de endogamia da geração dos genitores (F) foi comparado com o coeficiente de endogamia aparente das progênies $\left(\mathrm{F}_{\mathrm{ap}}\right)$ para uma verificação do equilíbrio de endogamia (Wright) da população, o qual foi calculado pela seguinte expressão:

$\mathrm{F}_{\mathrm{ap}}=(1-\mathrm{tm}) /(1+\mathrm{tm})$.

\section{Resultados e Discussão}

Das bandas obtidas com os oito primers, 56 foram analisadas, obtendo-se $78,57 \%$ de polimorfismo para todas as populações. Dentro de cada população, a taxa de polimorfismo foi menor que 60\% (Figura 1). Estes resultados demonstram haver variabilidade genética para a espécie. A Figura 2 mostra o padrão de bandas amplificadas com o primer OP-D11, para quatro populações.

$\mathrm{O}$ agrupamento genético das populações resultou em dois grupos (Figura 3), correspondentes às duas regiões geopolíticas do Vale do Rio Acre: o Alto Acre e o Baixo Acre. Houve, também, uma tendência de as populações se agruparem de acordo com suas localizações geográficas, evidenciando certa estruturação espacial da variabilidade genética. A análise da correlação entre as distâncias genéticas e geográficas de cada par de populações foi altamente significativa $(r=0,77 ; p<0,001)$, confirmando esta estruturação (Figura 4).

A maior parte da variação genética total de P. hispidinervum está dentro das populações (Tabela 2), e cerca de $28 \%$ dessa variação foi detectada entre populações.

A estrutura genética determinada por meio das estimativas das frequiências alélicas, pressupondo equilíbrio de Hardy-Weimberg, foi semelhante àquela definida pela AMOVA, com uma menor diferenciação entre regiões. Embora a metodologia baseada na análise de marcadores dominantes possa causar sérios vieses nas estimativas de parâmetros genéticos populacionais, os resultados

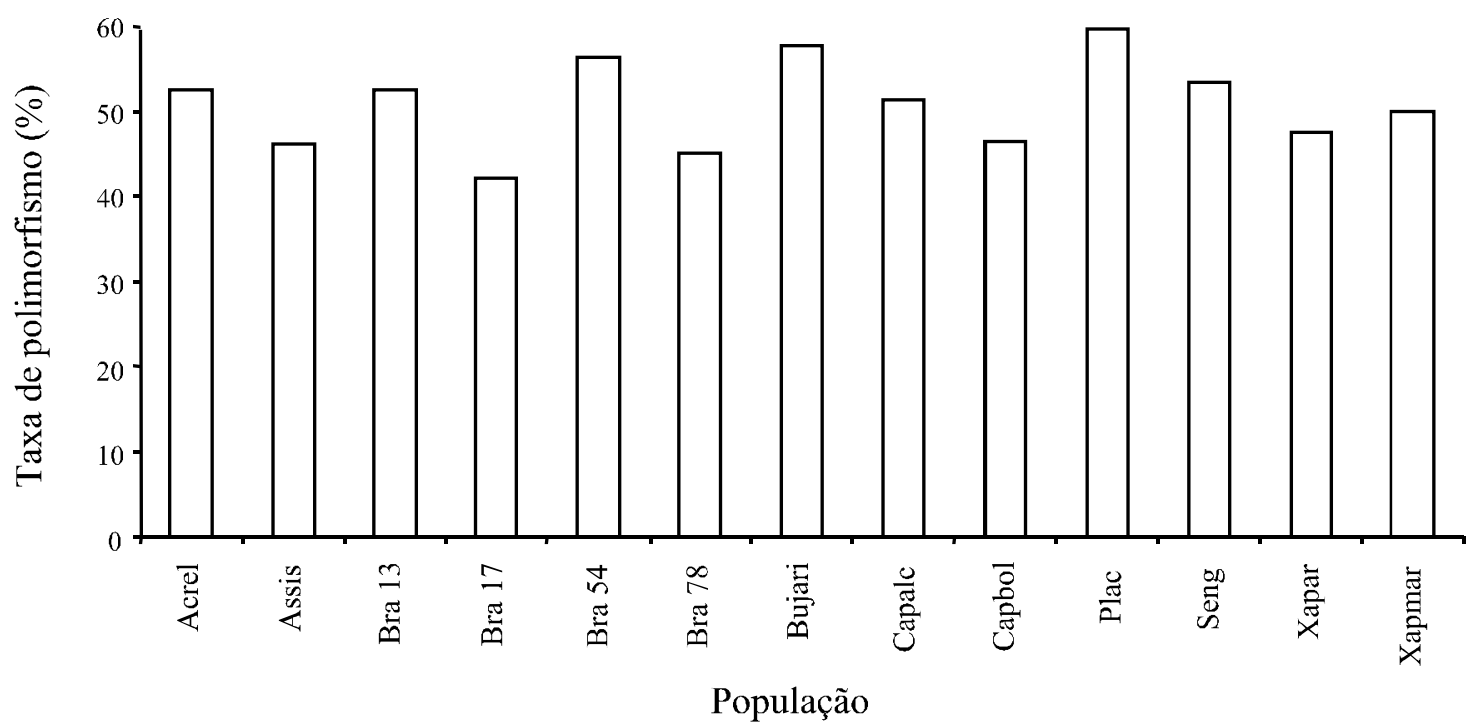

Figura 1. Taxa de polimorfismo para cada população natural de Piper hispidinervum amostrada no Vale do Rio Acre, AC. 
foram consistentes. Alguns trabalhos, com outras espécies vegetais, demonstraram que marcadores dominantes (RAPD) e co-dominantes (isoenzimáticos) podem gerar níveis de diversidade e diferenciação entre populações similares (Bucci et al., 1997; Ayres \& Ryan, 1999).

A taxa de polimorfismo observada em cada uma das regiões (Alto e Baixo Acre) foi equivalente. Por outro lado, analisando-se as freqüências dos marcadores RAPD, observa-se que as duas regiões apresentam distribuição diferenciada dessas freqüências (Figura 5).

A dispersão de sementes de $P$. hispidinervum é feita principalmente por morcegos, podendo iniciar populações com base genética restrita caso ocorram poucos episódios de dispersão (Fleming \& Heithaus, 1981; Hamrick \& Loveless, 1986). Neste estudo, é provável que a diferenciação genética observada entre as populações e regiões ocorra em virtude do efeito fundador, isto é, populações originadas por um conjunto de sementes com características genéticas semelhantes entre si, mas diferentes dos outros conjuntos.
Heywood \& Fleming (1986) também verificaram diferenciação genética entre populações, para três espécies de Piper, na Costa Rica, onde a dispersão de sementes é feita exclusivamente por morcegos. Como P. hispidinervum é uma espécie pioneira que coloniza rapidamente grandes áreas, gerando populações densas com banco de sementes restrito, cuja a germinação é muito dependente de luz, a sobreposição de gerações no banco de sementes deve ser pequena, contribuindo para certa homogeneidade da população e conseqüente diferenciação entre populações.

Resultados similares aos deste estudo foram observados para a espécie Piper cernnun (Mariot, 2000), em que a diferenciação genética entre quatro populações da Mata Atlântica foi elevada $\left(F_{S T}=0,29\right)$, com forte estruturação espacial.

Trabalhos semelhantes, conduzidos com outras espécies de plantas pioneiras de fecundação cruzada (Alvarez-Buylla \& Garay, 1994; Keys \& Smith, 1994), demonstram valores de $\mathrm{F}_{\mathrm{ST}}$ menores. Uma hipótese a

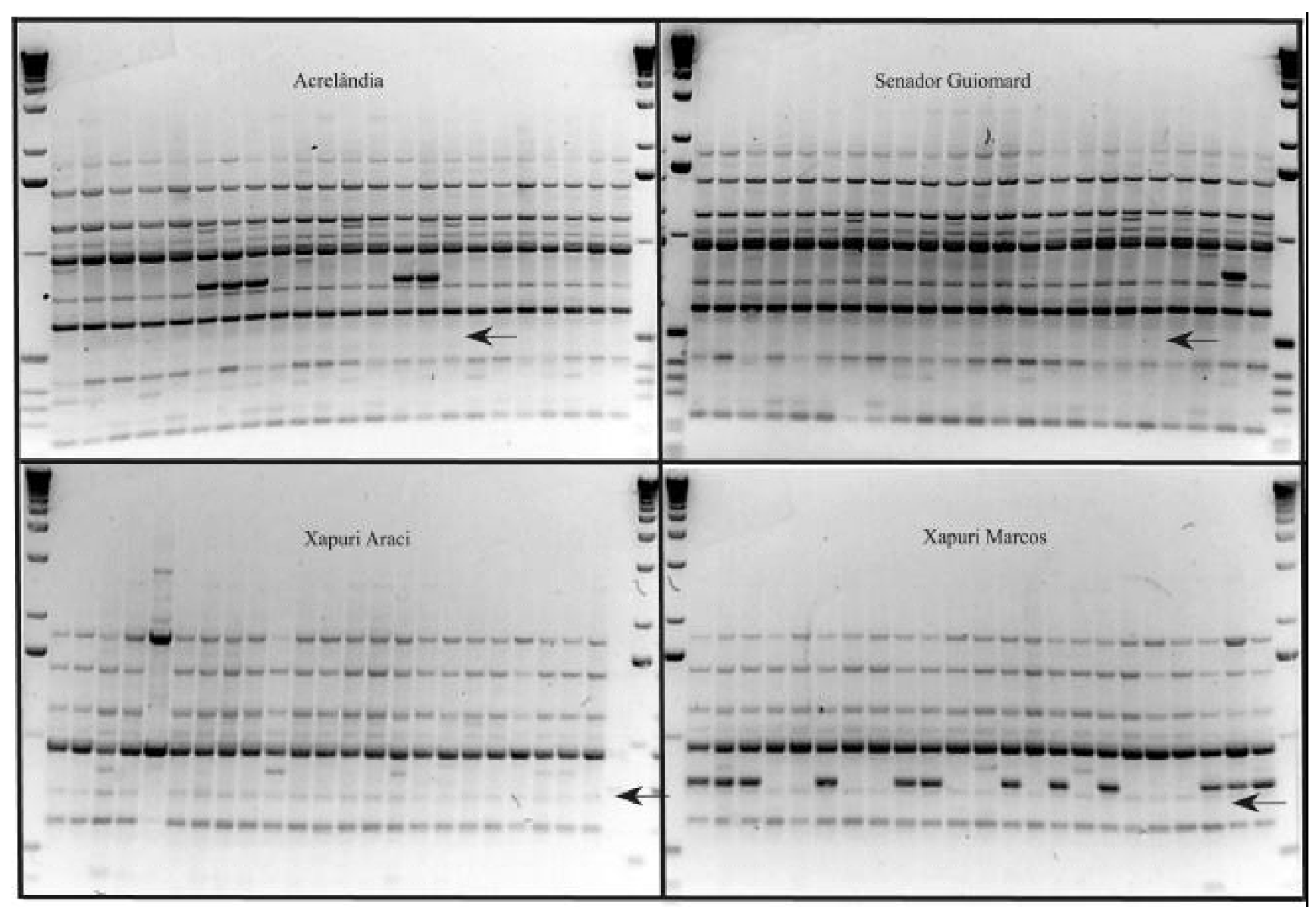

Figura 2. Padrão de bandas (marcadores RAPD) amplificadas com o primer OP-D11 e indivíduos das populações naturais de pimenta longa de Acrelândia, Senador Guiomard, Xapuri Araci e Xapuri Marcos. As setas indicam um dos locos RAPD analisados. 
ser testada para explicar esses dois padrões estaria relacionada às diferentes dinâmicas de extinção e recolonização, associadas com o tipo de banco de sementes no solo. $\mathrm{O}$ banco de sementes permanente favorece a sobreposição de gerações, minimizando o efeito fundador, enquanto este efeito é mais pronunciado quando o banco de sementes é restrito.

As estimativas de tm e ts foram 1,033 e 1,139, respectivamente, mostrando que a população estudada é predominantemente alógama. A diferença tm - ts foi -0,096, indicando que os cruzamentos ocorrem preferencialmen-

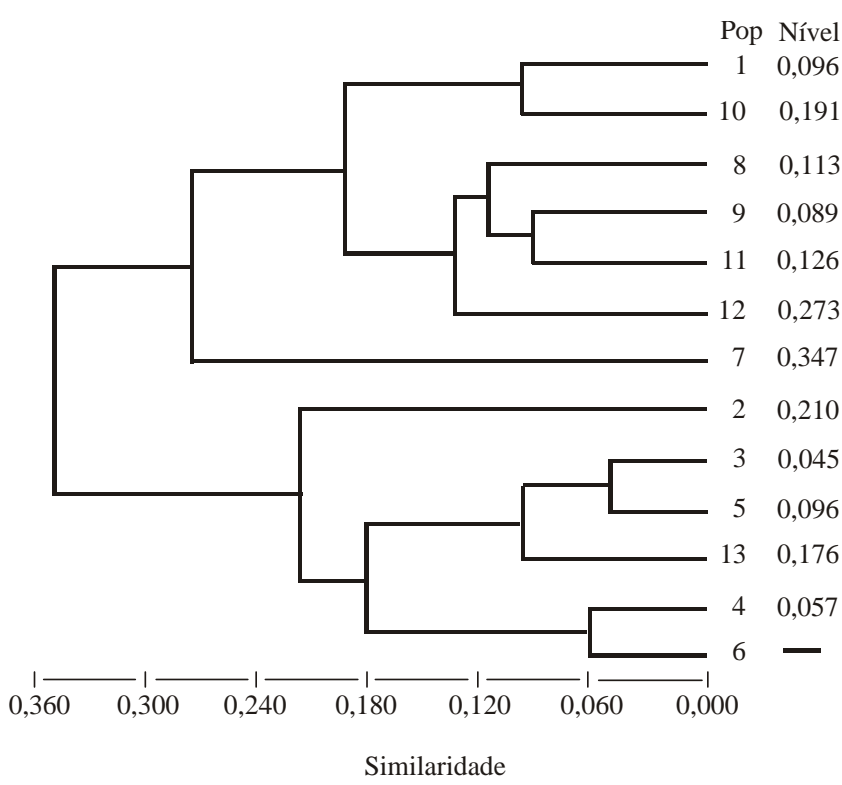

Figura 3. Dendrograma obtido pelo método UPGMA, apresentando o agrupamento das distâncias genéticas $\left(\phi_{\mathrm{ST}}\right)$ entre pares de populações de Piper hispidinervum do Vale do Rio Acre. Os números representam populações de, Acrelândia (1), Assis Brasil (2), Brasiléia, Bra 13 (3), Brasiléia, Bra 17 (4), Brasiléia, Bra 54 (5), Brasiléia, Bra 78 (6), Bujari (7), Capalc (8), Capbol (9), Plácido de Castro (10), Senador Guiomard (11), Xapar (12) e Xapmar (13). te entre indivíduos não-aparentados. O coeficiente de endogamia $\mathrm{F}$ foi 0,05 , evidenciando uma condição de panmixia da população, ou seja, os cruzamentos são aleatórios. O modo de reprodução por cruzamento foi bastante consistente de família para família.

A população amostrada apresentou freqüências genotípicas (estimadas a partir dos dados das progênies) semelhantes às esperadas para o equilíbrio de HardyWeinberg.

O gênero Piper contém mais de 700 espécies distribuídas em regiões tropicais e subtropicais do mundo inteiro, em que têm sido constatadas tanto espécies autógamas como alógamas. Apenas três espécies de Piper foram estudadas quanto à auto-incompatibilidade, $P$. methysticum se mostrou auto-incompatível (Prakash et al., 1994) e P. nigrum e P. arieianum são autocompatíveis (Martin \& Gregory, 1962; Marquis, 1988).

Estudos sobre a produção de sementes em plantas isoladas ou infrutescências ensacadas de P. hispidinervum (Silva \& Oliveira, 2000) evidenciaram a presença de mecanismo biológico que evita a autofecundação. Este trabalho mostrou essa mesma tendência, evidenciando que existe uma preferência para

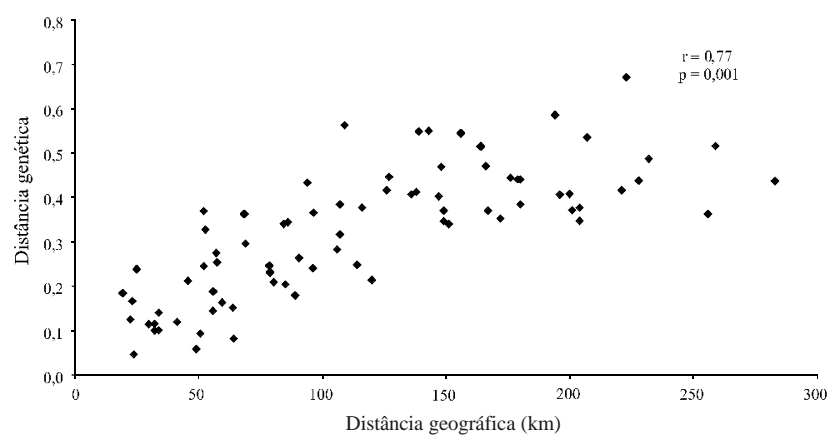

Figura 4. Dispersão dos dados da matriz de correlação das distâncias genética $\left(\phi_{\mathrm{ST}}\right)$ e geográfica dos pares de populações naturais de pimenta-longa do Vale do Rio Acre.

Tabela 2. Análise de variância molecular (AMOVA) intra e interpopulacional de Piper hispidinervum no Vale do Rio Acre, AC ${ }^{(1)}$.

\begin{tabular}{llccc}
\hline População & Fonte de variação & Variação genética (\%) & p & Estatística $\phi$ \\
\hline \multirow{2}{*}{ Todas (2 níveis) } & Entre populações & 28,10 & $<0,001$ & $\phi_{\mathrm{ST}}=0,281$ \\
& Entre indivíduos dentro de populações & 71,90 & - & - \\
\hline \multirow{2}{*}{ Todas (3 níveis) } & Entre regiões & 20,60 & $<0,001$ & $\phi_{\mathrm{CT}}=0,206$ \\
& Entre populações dentro de regiões & 14,33 & $<0,001$ & $\phi_{\mathrm{SR}}=0,180$ \\
& Entre indivíduos dentro de populações & 65,07 & $<0,001$ & $\phi_{\mathrm{ST}}=0,349$ \\
\hline
\end{tabular}

(1)Variação genética: porcentagem em relação ao total; p: nível de significância das estimativas de cada variação genética; estatística $\phi$ : variação genética estimada para cada fonte da variação. 


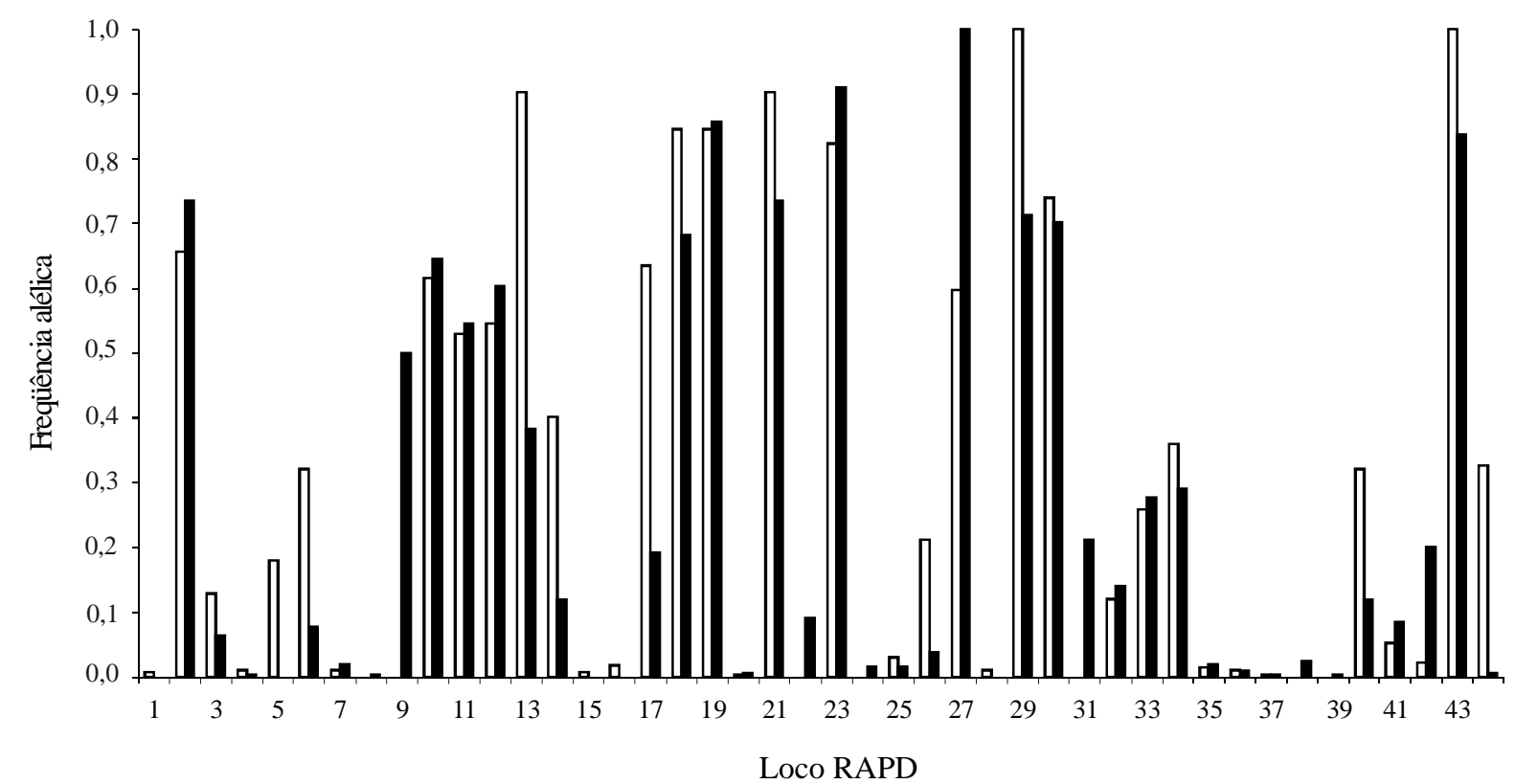

Figura 5. Frequiência de cada loco RAPD, com base nas estimativas das frequiências alélicas, segundo método proposto por Lynch \& Milligan (1994), para as populações naturais de Piper hispidinervum das regiões do Alto Acre ( $\square$ ) e Baixo Acre (ם).

cruzamento entre indivíduos não-aparentados. Características biológicas particulares de P. hispidinervum podem sugerir uma possível auto-incompatibilidade.

\section{Conclusões}

1. A espécie Piper hispidinervum apresenta estrutura genética que se enquadra no modelo de isolamento por distância.

2. Piper hispidinervum é, preferencialmente, de fecundação cruzada.

\section{Agradecimentos}

Ao DFID (Department for International Development) pelo apoio financeiro; ao técnico agrícola Rubens Mamedio Barros pelo apoio durante as coletas de campo; aos técnicos do Laboratório de Reprodução e Genética de Espécies Arbóreas (LARGEA) da USP-ESALQ pelas condições oferecidas durante as análises de RAPD.

\section{Referências}

ALMEIDA, M.C. Banco de sementes e simulação de clareiras na germinação de pimenta-longa (Piper hispidinervum C. DC.). 1999. 60p. Dissertação (Mestrado) - Universidade Federal do Acre, Rio Branco.
ALVAREZ-BUYLLA, E.R.; GARAY, A.A. Population genetic structure of Cecropia obtusifolia a tropical pioneer tree species. Evolution, v.48, p.437-453, 1994.

AYRES, D.R.; RYAN, F.J. Genetic diversity and structure of the narrow endemic Wyethia reticulata and its congener W. bolanderi (Asteraceae) using RAPD and allozyme techniques. American Journal of Botany, v.86, p.344-353, 1999.

BARRETT, S.C.H.; KOHN, J.R. Genetic and evolutionary consequences to small populations size in plants: implications for conservation. In: FALK, D.A.; HOLSINGER, K.E. (Ed.). Genetics and conservation of rare plants. New York: Oxford University Press, 1991. p.3-30.

BEKESSY, S.A.; ENNOS, R.A.; BURGMAN, M.A.; NEWTON, A.C.; ADES, P.K. Neutral DNA markers fail to detect genetic divergence in an ecologically important trait. Biological Conservation, v.110, p.267-275, 2003.

BUCCI, G.; VENDRAMIN, G.G.; LELLI, L.; VICARIO, F. Assessing the genetic divergence of Pinus leucodermis Ant. endangered populations: use of molecular markers for conservation purposes. Theoretical and Applied Genetics, v.95, p.1138-1146, 1997.

FERREIRA, M.E.; GRATTAPAGLIA, D. Introdução ao uso de marcadores moleculares em análise genética. 2.ed. Brasília: Embrapa-Cenargen, 1996. 220p.

FLEMING, T.H.; HEITHAUS, E.R. Frugivorous bats, seed shadows, and the structure of tropical forests. Biotropica Supplement, v.13, p.45-53, 1981.

GAIOTTO, F.A.; BRAMUCCI, M.; GRATTAPAGLIA, D. Estimation of outcrossing rate in a breeding population of Eucalyptus urophylla with dominant RAPD and AFLP markers. Theoretical and Applied Genetics, v.95, p.842-849, 1997. 
GJURIC, R.; SMITH JUNIOR, S.R. Identification of cross-pollinated and self-pollinated progeny in alfalfa through RAPD nulliplex loci analysis. Crop Science, v.36, p.389-393, 1996.

HAMRICK, J.L. The distribution of genetic variation within and among natural plant populations. In: SHONEWALD-COX, C.M.; CHAMBERS, S.M.; MacBIDE, B.; THOMAS, W.L. (Ed.). Genetics and conservation: a reference for managing wild animal and plant population. Menlo Park: Benjamin/Cummings, 1983. 335-348.

HAMRICK, J.L.; LOVELESS, M.D. The influence of seed dispersal mechanisms on the genetic structure of plant populations. In: ESTRADA, A.; FLEMING, T.H. (Ed.). Frugivores and seed dispersal. Dordrecht: Kluwer Academic, 1986. p.211-223.

HEYWOOD, J.S.; FLEMING, T.H. Patterns of allozyme variation in three Costa Rican species of Piper. Biotropica, v.18, p.208-213, 1986.

KAGEYAMA, P.Y.; FREIXÊDAS, V.M.; GERES, W.L.A.; DIAS, J.H.P.; BORGES, A.S. Consórcio de espécies nativas de diferentes grupos sucessionais em Teodoro Sampaio-SP. Revista do Instituto Florestal, v.4, p.527-533, 1992. Número único. Edição Especial.

KELLER, B.E.M. Genetic variation among and within populations of Phragmetis australis in the Charles River watershed. Aquatic Botany, v.66, p.195-208, 2000.

KEYS, R.N.; SMITH, S.E. Mating system parameters and population genetic structure in pioneer populations of Prosopis velutina (Leguminosae). American Journal of Botany, v.81, p.1013-1020, 1994.
LYNCH, M.; MILLIGAN, B.G. Analysis of population genetic structure with RAPD markers. Molecular Ecology, v.3, p.91-99, 1994.

MARIOT, A. Distribuição da diversidade genética e aspecto da fenologia e dispersão de sementes da pariparoba (Piper cernnun). 2000. 110p. Dissertação (Mestrado) - Universidade Federal de Santa Catarina, Florianópolis.

MARQUIS, R.J. Phenological variation in the neotropical understory shrub Piper arieianum: causes and consequences. Ecology, v.69, p.1552-1565, 1988.

MARTIN, F.W.; GREGORY, L.E. Mode of pollination and factors effecting fruit set in Piper nigrum L. in Puerto Rico. Crop Science, v.2, p.295-299, 1962.

PRAKASH, N.; BROWN, J.F.; YEU-HUA, W. An embryological study of kava, Piper methysticum. Australian Journal of Botany, v.42, p.231-237, 1994.

RITLAND, K. A series of FORTRAN computer programs for estimating plant mating systems. Journal Heredity, v.82, p.235-237, 1990.

SILVA, A.C.P.R. da; OLIVEIRA, M.N. de. Produção e dispersão de sementes de pimenta-longa (Piper hispidinervum). Rio Branco: Embrapa-CPAF Acre, 2000. 14p. (Boletim de Pesquisa, 24).

WEIR, B.S.; COCKERHAM, C.C. Estimating F-statistics for the analysis of populations structure. Evolution, v.38, p.1358-1370, 1984.

Recebido em 26 de fevereiro de 2003 e aprovado em 4 de novembro de 2003 